\title{
Validation of oral fluid samples to monitor serological changes to Plasmodium falciparum: An observational study in southern Zambia
}

\author{
Alexis P Chidi', Sandra Chishimba², Tamaki Kobayashi ${ }^{1}$, Harry Hamapumbu², Sungano Mharakurwa ${ }^{1,2}$, \\ Philip E Thuma ${ }^{2}$ and William J Moss ${ }^{{ }^{*}}$
}

\begin{abstract}
Background: In formerly endemic areas where malaria transmission has declined, levels of population immunity to Plasmodium falciparum provide information on continued malaria transmission and potentially susceptible populations. Traditional techniques for measuring serological responses to $P$. falciparum antigens use plasma or dried blood spots (DBS). These invasive procedures pose a biohazard and may be unacceptable to communities if performed frequently. The use of oral fluid (OF) samples to detect antibodies to $P$. falciparum antigens may be a more acceptable strategy to monitor changes in population immunity.

Methods: An enzyme immunoassay was optimized to detect antibodies to whole, asexual stage $P$. falciparum antigens. Optical density (OD) values from paired DBS and OF samples collected as part of a community-based survey of malaria parasitaemia were compared.

Results: Oral fluid and dried blood spot samples were collected from 53 participants in Southern Province, Zambia. Their ages ranged from 1 to 80 years and 45\% were female. A statistically significant correlation $(r=0.79 ; P<0.01)$ was observed between OD values from OF and DBS samples. The OF assay identified all DBS-confirmed positive and negative samples, resulting in $100 \%$ sensitivity and specificity.

Conclusions: Oral fluid is a valid alternative specimen for monitoring changes in antibodies to $P$. falciparum antigens. As OF collection is often more acceptable to communities, poses less of a biohazard than blood samples and can be performed by community volunteers, serological surveys using OF samples provide a strategy for monitoring population immunity in regions of declining malaria transmission.
\end{abstract}

\section{Background}

In formerly malaria endemic areas where transmission has declined, changing levels of population immunity to Plasmodium falciparum provide information on foci of malaria transmission and potentially susceptible populations [1]. Serological studies can reveal more than the point prevalence of malaria and reflect secular trends in the level of exposure, and are thus less affected by seasonal variations in transmission [1,2]. Traditional serological techniques using plasma samples or dried blood spots (DBS) to detect antibodies to $P$. falciparum antigens pose

\footnotetext{
* Correspondence: wmoss@jhsph.edu

'Johns Hopkins Bloomberg School of Public Health, Baltimore, MD, USA Full list of author information is available at the end of the article
}

a biohazard and may be unacceptable to communities if performed frequently [3].

Oral fluid (OF) refers to crevicular fluid, the transudate from the crevice between the gum margin and teeth, collected from the mouth using an absorptive device [4]. Crevicular fluid contains the highest concentration of immunoglobulins outside the blood, although these levels are approximately $1 / 1,000$ of the concentration found in plasma. OF collection is less invasive and may encourage participation among groups such as children, pregnant women and the elderly, who may be averse to phlebotomy [5]. OF collection allows for sampling to be conducted by lower level health care workers or community volunteers, and poses a less significant biohazard than DBS collection or phlebotomy. OF has been used routinely to detect

\section{() Biomed Central}


antibodies to human immunodeficiency [6], measles [7] and rubella [8] viruses among other pathogens.

The use of OF specimens to monitor changes in antibody levels to $P$. falciparum antigens may be a more acceptable strategy to monitor changes in population immunity, particularly in regions of declining malaria transmission. However, no published evidence exists on the use of $\mathrm{OF}$ to detect antibodies to P. falciparum. The use of OF samples to measure antibody levels to P. falciparum antigens was validated in a region of declining malaria transmission in southern Zambia.

\section{Methods}

The study was conducted in the catchment area of Macha Hospital in Southern Province, Zambia. Macha Hospital is approximately $70 \mathrm{~km}$ from the nearest town of Choma and the catchment area is populated by traditional villagers living in small, scattered homesteads. Anopheles arabiensis is the primary vector responsible for malaria transmission [9], which peaks during the rainy season from December through April. Over the past decade the Southern Province of Zambia has experienced a substantial decline in the burden of malaria [10].

Satellite images were used to construct a sampling frame for the random selection of households. Permission from the chief and head of household were obtained prior to the study visits. Field workers obtained individual informed consent and a questionnaire was administered to each study participant to collect demographic information as well as information on prior malaria infections and treatment history. Blood samples were collected by finger prick and stored as DBS on filter paper (Whatman, Protein Saver card 903). The cards were dried overnight and stored individually with desiccant in sealed plastic bags. OF samples were obtained from the same participants using Aware Messenger oral-specimen collection devices (Calypte Biomedical Corporation, Portland, OR, USA). Participants' gums were swabbed for one minute according to the manufacturer's instructions, and samples were transferred to a collection tube with the manufacturer's transport buffer.
Samples were stored at room temperature. The study was approved the Johns Hopkins Bloomberg School of Public Health Institutional Review Board and the University of Zambia Research Ethics Committee.

An enzyme immunoassay (EIA) was used to detect antibodies to whole, asexual stage $P$. falciparum antigens with known positive and negative control samples (Table 1). Sera were eluted from DBS using 5\% skim milk in phosphate buffered saline with $0.05 \%$ Tween 20 (PBST). OF samples were centrifuged for 5 minutes at $14,000 \mathrm{rpm}$ and $75 \mu \mathrm{L}$ of the supernatant was added to $25 \mu \mathrm{L}$ of $10 \%$ skim milk with PBST in each well before the plate was incubated for 15 hours at $4^{\circ} \mathrm{C}$. Whole $P$. falciparum asexual stage antigens were coated on a flat-bottomed 96 well plate (Thermo, Immulon 2HB) overnight at $4^{\circ} \mathrm{C}$. The plate was blocked using $5 \%$ skim milk with phosphate buffered saline for one hour at $37^{\circ} \mathrm{C}$. Serum and $\mathrm{OF}$ samples were plated in triplicate and incubated for one hour at $37^{\circ} \mathrm{C}$, and peroxidaselabeled goat anti-human IgG was added to the plate for one hour at $37^{\circ} \mathrm{C}$. ABTS was added to the plate for 15 minutes at room temperature before the optical density (OD) was read at $405 \mathrm{~nm}$.

To classify samples as seropositive or seronegative, test results were compared to a threshold OD level established as three standard deviations above the OD observed from filter paper spotted with serum from individuals who reported never having been exposed to malaria. OD values from paired DBS and OF samples were compared using Stata version 11.0 and the correlation coefficient was computed.

\section{Results}

Oral fluid and dried blood spot samples were collected from 53 participants in Southern Province, Zambia. Their ages ranged from 1 to 80 years and $45 \%$ were female. The median age was 13.5 years and $17 \%$ were younger than five years of age. A statistically significant correlation $\left(\mathrm{r}=0.79, \mathrm{r}^{2}=0.63, \mathrm{P}<0.01\right)$ was observed between OD values obtained from OF and DBS samples (Figure 1). When the single outlier was excluded from analysis, the correlation improved $\left(r=0.84, r^{2}=0.71\right)$.

Table 1 Optimization conditions for oral fluid enzyme immunoassay

\begin{tabular}{ll}
\hline Variable & Conditions Tested \\
\hline Volume of solution in well & $100 \mu \mathrm{L}$ or $200 \mu \mathrm{L}$ \\
Incubation time & $1,2,6,8$, or 15 hours \\
Incubation temperature & $4^{\circ} \mathrm{C}$ or $37^{\circ} \mathrm{C}$ \\
Dilution & OF alone, $1: 2,1: 4$ with PBST, $5 \%$ skim milk PBST \\
Proportion of sample on plate & $75 \mu \mathrm{L}$ OF $+25 \mu \mathrm{L}$ diluent or $50 \mu \mathrm{L}$ OF $+50 \mu \mathrm{L}$ diluent \\
Centrifugation (5 min at $14000 \mathrm{rpm})$ & None, supernatant, resuspended pellet \\
\hline
\end{tabular}

OF $=$ oral fluid

PBST $=$ phosphate buffered saline with $0.05 \%$ Tween 20 


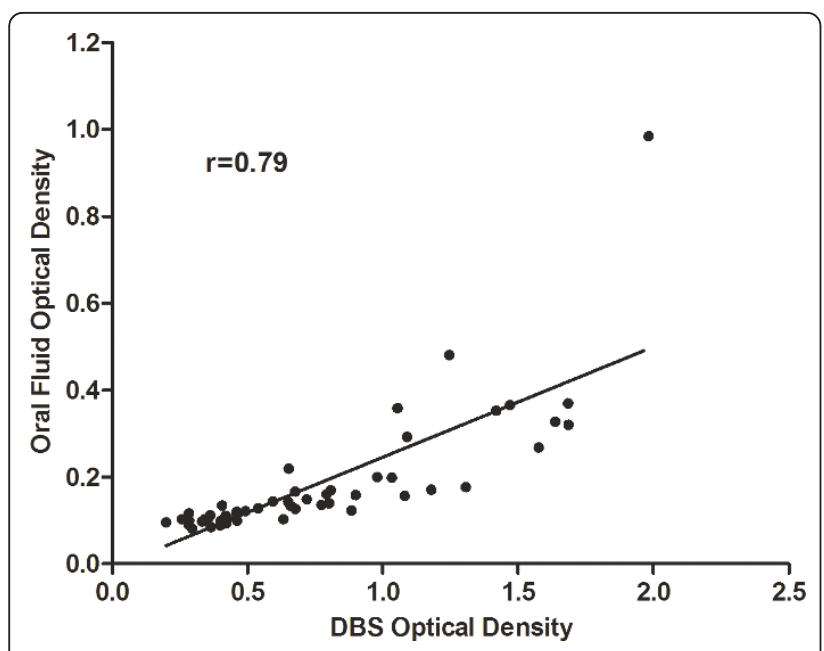

Figure 1 Scatter plot showing correlation between optical density values obtained using oral fluid and dried blood spot samples.

However, OD values obtained from OF samples were consistently lower than those obtained from DBS. The OF assay identified all DBS-confirmed positive and negative samples, resulting in $100 \%$ sensitivity and specificity (Figure 2).

\section{Discussion}

These results suggest that $\mathrm{OF}$ is a valid alternative specimen for monitoring changes in antibodies to P. falciparum. OF samples are likely to be more acceptable for community surveillance, particularly in areas of declining malaria transmission and when repeated measures are desired. As OF collection poses less of a biohazard than blood samples, and can be performed by unskilled volunteer health workers as part of task shifting [11],

\begin{tabular}{|c|c|c|c|c|}
\hline \multicolumn{5}{|c|}{ Dried Blood Spots } \\
\hline \multirow{4}{*}{$\frac{\text { 음 }}{\frac{\bar{D}}{\bar{\square}}}$} & & Positive & Negative & Total \\
\hline & Positive & 24 & 0 & 24 \\
\hline & Negative & 0 & 29 & 29 \\
\hline & Total & 24 & 29 & 53 \\
\hline \multicolumn{5}{|c|}{ Sensitivity $=24 / 24=100 \%$} \\
\hline & \multicolumn{4}{|c|}{ Specificity $=29 / 29=100 \%$} \\
\hline \multicolumn{5}{|c|}{$\begin{array}{l}\text { Figure } 2 \text { Comparison of enzyme immunoassay results using } \\
\text { oral fluid and dried blood spots. }\end{array}$} \\
\hline
\end{tabular}

the use of OF for antibody determination allows for frequent testing in resource-limited settings.

OF samples have been used for serological surveillance of a variety of infections [12], and have been used to detect $P$. falciparum DNA by polymerase chain reaction [13-15] and histidine-rich protein 2 by EIA [16]. These results suggest that OF samples also can be used to monitor changes in population immunity as a component of malaria surveillance programs. The major limitation of OF samples is the difficulty in assessing whether an adequate sample was collected. Detection of total IgG is one strategy to identify improperly collected samples [7].

\section{Conclusions}

OF sampling provides an alternative method of conducting surveillance for malaria population immunity and transmission. As malaria control programmes successfully reduce transmission, surveillance will be increasingly important to guide control strategies. The use of OF samples could make repeated surveys acceptable and feasible in low-resource settings.

\section{Abbreviations}

ABTS: 2,2'-azino-bis(3-ethylbenzthiazoline-6-sulphonic acid); DBS: dried blood spots; EIA: enzyme immunoassay; OD: optical density; OF: oral fluid; PBST: phosphate buffered saline with $0.05 \%$ Tween 20

\section{Acknowledgements and Funding}

We thank the communities, headmen and chiefs of Macha, Mapanza, Muchila and Chikanta for agreeing to participate in this study. We are grateful to the field team for their invaluable contributions to sample and data collection. This project was funded by the Johns Hopkins Center for Global Health (APC) and the Johns Hopkins Malaria Research Institute and the Bloomberg Family Foundation (WJM).

This work was presented in part at the American Society of Tropical Medicine and Hygiene $59^{\text {th }}$ Annual Meeting, Atlanta, Georgia, November 3-7, 2010 (Abstract \# LB-2261)..

\section{Author details}

'Johns Hopkins Bloomberg School of Public Health, Baltimore, MD, USA. ${ }^{2}$ Macha Research Trust, Choma, Zambia.

\section{Authors' contributions}

APC performed the enzyme immunoassays and drafted the manuscript. SC performed and supervised the enzyme immunoassays. TK designed the experiments, supervised the enzyme immunoassays and participated in the preparation of the manuscript. $\mathrm{HH}$ participated in the design and coordination of the data and sample collection. SM participated in the design and coordination of the study. PET participated in the design and coordination of the study. WJM conceived of the study, participated in its design and coordination, and drafted the manuscript. All authors read and approved the final manuscript.

\section{Competing interests}

The authors declare that they have no competing interests.

Received: 7 March 2011 Accepted: 10 June 2011

Published: 10 June 2011

\section{References}

1. Webster HK, Gingrich JB, Wongsrichanalai C, Tulyayon S, Suvarnamani A, Sookto P, Permpanich B: Circumsporozoite antibody as a serologic 
marker of Plasmodium falciparum transmission. Am J Trop Med Hyg 1992, 47:489-497.

2. Drakeley CJ, Corran PH, Coleman PG, Tongren JE, McDonald SL, Carneiro I, Malima R, Lusingu J, Manjurano A, Nkya WM, Lemnge MM, Cox J, Reyburn H, Riley EM: Estimating medium- and long-term trends in malaria transmission by using serological markers of malaria exposure. Proc Natl Acad Sci USA 2005, 102:5108-5113.

3. Spielberg F, Critchlow C, Vittinghoff E, Coletti AS, Sheppard H, Mayer KH, Metzgerg D, Judson FN, Buchbinder S, Chesney M, Gross M: Home collection for frequent HIV testing: acceptability of oral fluids, dried blood spots and telephone results. HIV Early Detection Study Group. AIDS 2000, 14:1819-1828.

4. McKie A, Vyse A, Maple C: Novel methods for the detection of microbial antibodies in oral fluid. Lancet Infect Dis 2002, 2:18-24.

5. Vyse AJ, Cohen BJ, Ramsay ME: A comparison of oral fluid collection devices for use in the surveillance of virus diseases in children. Public Health 2001, 115:201-207.

6. Roberts KJ, Grusky O, Swanson AN: Outcomes of blood and oral fluid rapid HIV testing: a literature review, 2000-2006. AIDS Patient Care STDS 2007, 21:621-637.

7. Lowther SA, Curriero FC, Kalish BT, Shields TM, Monze M, Moss WJ: Population immunity to measles virus and the effect of HIV-1 infection after a mass measles vaccination campaign in Lusaka, Zambia: a crosssectional survey. Lancet 2009, 373:1025-1032.

8. Manikkavasagan G, Bukasa A, Brown KE, Cohen BJ, Ramsay ME: Oral fluid testing during 10 years of rubella elimination, England and Wales. Emerg Infect Dis 2010, 16:1532-1538.

9. Kent RJ, Thuma PE, Mharakurwa S, Norris DE: Seasonality, blood feeding behavior, and transmission of Plasmodium falciparum by Anopheles arabiensis after an extended drought in southern Zambia. Am J Trop Med Hyg 2007, 76:267-274.

10. Ministry of Health Government of the Republic of Zambia: Zambia National Malaria Indicator Survey 20102010.

11. Nsubuga $\mathrm{P}$, Nwanyanwu $\mathrm{O}$, Nkengasong JN, Mukanga D, Trostle M: Strengthening public health surveillance and response using the health systems strengthening agenda in developing countries. BMC Public Health 2010, 10(Suppl 1):S5.

12. Lima DP, Diniz DG, Moimaz SA, Sumida DH, Okamoto AC: Saliva: reflection of the body. Int J Infect Dis 2010, 14:e184-e188.

13. Mharakurwa S, Simoloka C, Thuma PE, Shiff CJ, Sullivan DJ: PCR detection of Plasmodium falciparum in human urine and saliva samples. Malar $J$ 2006, 5:103.

14. Nwakanma DC, Gomez-Escobar N, Walther M, Crozier S, Dubovsky F, Malkin E, Locke E, Conway DJ: Quantitative detection of Plasmodium falciparum DNA in saliva, blood, and urine. J Infect Dis 2009, 199:1567-1574.

15. Buppan P, Putaporntip C, Pattanawong U, Seethamchai S, Jongwutiwes S: Comparative detection of Plasmodium vivax and Plasmodium falciparum DNA in saliva and urine samples from symptomatic malaria patients in a low endemic area. Malar J 2010, 9:72.

16. Wilson NO, Adjei AA, Anderson W, Baidoo S, Stiles JK: Detection of Plasmodium falciparum histidine-rich protein II in saliva of malaria patients. Am J Trop Med Hyg 2008, 78:733-735.

doi:10.1186/1475-2875-10-162

Cite this article as: Chidi et al: Validation of oral fluid samples to monitor serological changes to Plasmodium falciparum:

An observational study in southern Zambia. Malaria Journal 2011 10:162.

\section{Submit your next manuscript to BioMed Central and take full advantage of:}

- Convenient online submission

- Thorough peer review

- No space constraints or color figure charges

- Immediate publication on acceptance

- Inclusion in PubMed, CAS, Scopus and Google Scholar

- Research which is freely available for redistribution 